\title{
El vídeo como soporte en la narrativa digital del Branded Content y los productos audiovisuales en las plataformas online
}

\section{Video as support in the digital narrative of Branded Content and audiovisual products on online platforms}

\section{Francisco Javier Montemayor Ruiz (España)}

montemayor.tv@gmail.com

Universidad Francisco de Vitoria de Madrid Doctor en Comunicación Audiovisual, Publicidad y Relaciones Públicas

\author{
Miguel Ángel Ortiz Sobrino (España) \\ maortiz@ucm.es \\ Universidad Complutense de Madrid \\ Doctor en Ciencias de la Información
}

\section{Resumen}

Los relatos audiovisuales en soporte videográfico utilizados en la difusión de las marcas publicitarias están inmersos en

\section{Summary}

The audiovisual stories in video-graphic support that are used broadcasting advertising brands are immersed in a
9 DE NOVIEMBRE DE 2015

14 DE MARZO DE 2016

4 DE ABRIL DE 2016
Para Citar este artículo / to CITE thIS ARTICLE

Montemayor Ruiz, F. J. \& Ortiz Sobrino, M. A. (2016). El vídeo como soporte en la narrativa digital del Branded Content y los productos audiovisuales en las plataformas online, Poliantea, 12(22). 
un profundo proceso de transformación. El vídeo se ha consolidado como una herramienta fácilmente comprensible por el usuario y posee la facultad de poder viajar por diversas plataformas digitales generando millonarios impactos, sobre todo, gracias a Internet. Esta versatilidad del vídeo ha propiciado que las fórmulas narrativas tradicionales hayan superado el reto de la dimensión transmedia de los contenidos y que el branded content en soporte videográfico haya sido puesto en valor como un innovador instrumento de comunicación que las marcas publicitarias están utilizando para introducir sus mensajes dentro del contexto de la historia contada, utilizando diferentes plataformas digitales de distribución de contenidos.

Este estudio analiza el vídeo como el soporte más aceptado para consumir publicidad en formato branded content en tres campañas publicitarias de éxito, y se hace eco de dos estudios relativos al consumo de contenidos publicitarios en YouTube y Vimeo por medio de los smartphones y otros dispositivos de descarga de contenidos: canales y herramientas que permiten generar elementos de conexión esenciales entre el anunciante y sus públicos. Para este trabajo se ha utilizado un método basado en técnicas de observación y estudio de contenidos branded content en las plataformas online seleccionadas, para contextualizar, después, los resultados con los principales datos relativos al consumo publicitario online aportados por investigaciones realizadas por empresas de consultoría.

Previamente, mediante un proceso de revisión documental, se ha enmarcado profound transformation process. The video has been established as an easy understandable tool for the user and has the faculty for being able to travel on a variety of digital platforms generating millionaire impacts, above all, thanks to the Internet. This video versatility has meant that the traditional narrative formulas have overcome the challenge of transmedia dimension on content and that branded content in videographic support has been valued as an innovative communication instrument used by advertising brands to spread their messages within the narrative context, using different digital platforms for content distribution.

This study analyzes videos as the most accepted support to consume advertising within branded content format in three successful advertising campaigns, and echoes two studies related to content advertising consumption on YouTube and Vimeo using smartphones and other devices to download contents: these channels and tools that generate essential connection elements between the advertiser and audiences. For this purpose, we have used a method based on observation techniques and the study of branded content on the selected online platforms to contextualize the results with the main data related to online advertising consumption provided by researches carried out by consultancy firms. Previously, through a documentary review process, we have framed the communicative ecosystem of the new online platforms and the branded content formats as a content distribution support. Which was later improved within 
el ecosistema comunicativo de las nuevas plataformas online y los formatos branded content como soportes de distribución de contenidos. Después, se ha reparado en la innovación expresiva y el impacto mediático de los relatos de branded content en formato videográfico que circulan a través de las plataformas YouTube y Vimeo. Un formato en vídeo que se ha convertido en herramienta habitual en las estrategias de la narración digital para la optimización de las campañas de marketing transmedia o de publicidad de marcas.

Palabras clave: marketing transmedia, branded content, plataformas digitales, YouTube, vídeo online. expressive innovation and media impact on the branded content narrative in the video-graphic format which circulates through the YouTube and Vimeo platforms. This video format has become a common tool in the digital narrative strategy for optimizing Transmedia marketing campaigns or brand advertising.

Keywords: Marketing transmedia, branded content, digital platforms, YouTube, online video. 


\section{Introducción}

En esta segunda década del siglo y consumo de contenidos. Es neceXXI, las nuevas tecnologías están sario ser conscientes de que asisevolucionando exponencialmente $y$ afectan a todos los órdenes de nuestra vida cotidiana. En este proceso de digitalización permanente, los medios de comunicación tradicionales también se están reinventando para no perder el ritmo que están imponiendo otros canales de difusión. Hoy, los media se enfrentan a un individuo/usuario digital y online que se ha convertido en un nuevo consumidor que participa, produce contenido y requiere algo de los diferentes soportes comunicativos a cambio de su atención.

Vivimos un cambio estructural, transitando un paradigma dinámico donde la comunicación digital interactiva es un espacio de convergencia tecnológica y cultural, caracterizada por la presencia de tecnologías que afectan a la producción, distribución timos a procesos simultáneos de convergencia mediática, ya no solo digital ni mediática, sino social entre las esferas empresarial, política, profesional, de contenidos y desarrollo tecnológico. De ahí que la convergencia sea un proceso más cultural y transmediático que tecnológico (Irigaray, 2011).

En este nuevo escenario pueden destacarse diversos factores que inciden, directamente, en el nuevo paradigma de las narraciones digitales: el soporte de vídeo, los nuevos formatos audiovisuales en Internet, la producción de contenidos que se expanden por diversos medios y la búsqueda de las marcas anunciantes por integrar sus mensajes en los contenidos audiovisuales a través del branded content o branded entertainment. Este ecosistema digital se 
nutre de conceptos y términos que son habituales en todos los estudios académicos relacionados con el fenómeno de la nueva forma de comunicar: experiencia de usuario, interactividad, código textual, construcción de marca, audiencia social, engagement, redes sociales, multipantalla, estrategia de marketing, prosumidor, diseño multiplataforma, youtubers, etc. Una de las consecuencias de este nuevo ecosistema mediático ha sido la generalización del vídeo como contenedor de mensajes y soporte del branded content.

En el vídeo, dice Díaz Arias (2008), se dan dos grandes formatos narrativos: el segmento de corta duración y la narración propia de la ficción, algo más expandida. No obstante, la televisión aporta otro formato de gran concentración narrativa, el spot publicitario. Además, toda la narrativa televisiva se fragmenta por influjo de la emisión comercial publicitaria o promocional. Como apunta este autor: "La mayoría de los programas de televisión insertan segmentos o piezas de vídeo que concentran la atención en un aspecto particular" (Díaz Arias, 2008, p. 65).

Pero hoy, el vídeo viaja y se expande por todos los canales de difusión, ya sean tradicionales $o$ emergentes. El vídeo también eclosiona como el factor dominante en el ciberespacio. No obstante, si retrocedemos en el tiempo, dice Díaz Arias (2008), "hace diez años la World Wide Web estaba basada en textos, acompañados de fotos y gráficos. Pocos sitios ofrecían la posibilidad de descargar o visionar vídeos" (Díaz Arias, 2008, p. 64). Citando a Manovich (2001), Díaz Arias (2008, p. 64) señala que "los vídeos son hoy una parte sustancial de las interacciones que crean una información globalmente compartida a la que, según una metáfora espacial, llamamos ciberespacio, espacio navegable, espacio que podemos navegar gracias al lenguaje hipertextual".

Aunque navegando por la red podemos acceder a las grandes narrativas extendidas (películas, programas de televisión, programaciones completas), el producto más característico es el vídeo de corta duración (short format), un relato condensado que requiere una atención fugaz, apto para un consumo banal, compulsivo y fácilmente compartido mediante la difusión viral. Un buen ejemplo es el formato vídeoclip; aunque en la actualidad, incluso los grandes relatos, las grandes programaciones, 
también son fragmentadas en forma de píldoras que sustentan contenidos aislados de una misma historia pero persiguiendo la unidad narrativa total en forma de secuencias independientes.

Es en Internet, en la red, donde tanto los operadores de telecomunicaciones, los medios de comunicación de masas, las grandes marcas, los grupos multinacionales y las instituciones de todo tipo, han encontrado un verdadero filón que posibilita una triple oferta de acceso a Internet, smartphone y un paquete de canales de televisión. Sin embargo, y como resalta Bustamante (2008, p. 29), se trata de "una mera operación de marketing, sin inversión en nuevas programaciones". Pero más allá se encuentra el universo en continua expansión del cibervídeo, gracias a los contenedores o repositorios que permiten compartir vídeos y cuyo modelo es YouTube (Díaz Arias, 2008; Pérez Rufí y Gómez Pérez, 2013).

Las posibilidades de la Web 2.0, citando a Henry Jenkins (2007), son también el resultado de la necesidad de participación cultural de todo tipo durante décadas pasadas, que ha establecido el desarrollo y la rápida adopción de plataformas como
YouTube, con lo cual podemos concluir que la tecnología responde a las demandas de la sociedad y no al contrario.

El vídeo, señala Díaz Arias (2008):

Es también un nodo de conexión entre distintas redes sociales. El vídeo compite con la palabra escrita en la conversación global de los blogs. El vídeo es también un catalizador de la movilización del grupo. El vídeo es, en definitiva, uno de los grandes motores de las redes sociales (Díaz Arias, 2008, p. 67).

El usuario y el formato de vídeo como soporte de comunicación conforman la «clave de bóveda» del llamado «ecosistema digital» que, desarrollado fundamentalmente a través de Internet, se presenta en este estudio como el término aplicado para comprender el proceso que sirve a las marcas para posicionarse y darse a conocer frente a miles de potenciales usuarios que navegan por la web y las redes sociales. Un ecosistema que integra recursos y acciones para conseguir que el mensaje logre una comunicación mucho más efectiva que el marketing tradicional. Es en este nuevo espacio convergente 
donde el vídeo se ha posicionado como recurso expresivo fundamental y hegemónico de la publicidad de marcas, como lo demuestran su presencia en los new media vinculados a la Red, en las nuevas pantallas propiciadas por la telefonía móvil, en los social media, y en las diferentes soportes para el branded content en la publicidad dinámica.

Este estudio que ahora se presenta se centra en el vídeo online como soporte y catalizador de los contenidos audiovisuales de branded content distribuidos a través de Internet y en los nuevos formatos que surgen a raíz de la popularidad de un portal específico de contenidos de vídeo como es YouTube, y en segundo término, Vimeo. La presencia de YouTube como aplicación en dispositivos portátiles y smartphones o como operador de contenidos en Smart t $v$, convierte al portal de Google en una marca crossmedia, el referente del vídeo online (Pérez Rufí y Gómez Pérez, 2013).

\section{Marco teórico}

Nos encontramos inmersos en la era de la convergencia, donde han eclosionado "nuevos tipos de narrativas que, basadas en las nuevas tecnologías, ponen un énfasis especial en la actividad del lector/espectador/usuario" (Costa Sánchez y Piñeiro Otero, 2012, p. 103). Internet y las nuevas plataformas de distribución de contenidos han venido no solo a multiplicar las posibilidades de emisión de los mensajes, también han provocado la incorporación de nuevos formatos de comunicación y de nuevas formas de contar, más acordes a las nuevas posibilidades y hábitos de consumo. Esta transformación de los formatos narrativos en los media no es un fenómeno nuevo. Ya sucedió cuando la paleotelevisión se apropió del lenguaje y los formatos del cine y de la radio para construir su propio discurso audiovisual. Freitas y Castro (2010) dicen que un proceso similar ha aparecido, no hace mucho, "con el desarrollo de los medios digitales, donde el relato utilizado por estos nuevos medios de comunicación incorpora elementos del lenguaje de otros medios y formas de expresión" (Freitas y Castro, 2010, p. 21). También la irrupción masiva de los soportes computarizados contribuyó a estos cambios. Como señala Murray (2007), citado por Freitas y Castro (2010), la capacidad de almacenamiento y organización 
compleja del computador puede ser utilizada como apoyo de un universo narrativo denso y exigente.

Montemayor Ruiz (2015) dice que hoy es posible ofrecer un abanico de contenidos audiovisuales digitales mediante la utilización de servidores de enorme capacidad, facilitando considerablemente el registro, almacenamiento, edición online y confección de bloques selectivos en la narración gracias a un hardware y a un software específico que proporcionará el manejo, en tiempo real, de gran cantidad de datos que contienen información visual. "Se podría decir que estamos ante un nuevo escenario en la transmisión de mensajes cargados de códigos que enriquecen la experiencia del usuario, dotándole de enorme cantidad de información de forma simultánea" (Montemayor Ruiz, 2014, p. 53). Como sostiene Ràfols (2011), el desarrollo de la tecnología informática en el tratamiento, la manipulación y la creación de imágenes ha llegado a unos niveles que "representan un instrumento potencial de pleno derecho para ser considerado en la elaboración de la información diaria audiovisual" (Ràfols, 2011, p. 569).

La industria audiovisual se ha adecuado a estas formas de producir contenidos, especialmente en aquellas que utilizan diferentes soportes y lenguajes para construir el relato. En este contexto, productores y creadores han comenzado a idear nuevas formas de producción audiovisual en el entorno digital, donde los nuevos relatos se remiten a las estructuras narrativas que utilizan múltiples plataformas tecnológicas y de gestión de contenidos (Marta Lazo y Ortiz Sobrino, 2013). Expresiones como transmedia o crossmedia se utilizan con frecuencia para designar esta tipología de proyectos a los que se puede acceder desde diferentes plataformas de contenidos adecuados al lenguaje y a la forma de presentación de cada una de ellas.

\section{Un nuevo rol para los usuarios de la comunicación en la era digital}

Desde el punto de vista de la recepción, algunos estudios apuntan a la apropiación, por parte de la audiencia, de los nuevos medios digitales, incidiendo en el crecimiento de la experiencia interactiva e inmersiva a la que es sensible el consumidor. También se alude a la oportunidad de colaboración en la creación colectiva - que ya no está en poder exclusivo de las empresas 
de comunicación-, además de las posibilidades de visibilidad que las nuevas plataformas tecnológicas proporcionan al usuario (Freitas y Castro, 2010). Se trata de una nueva forma de disfrutar de los contenidos audiovisuales que aporta un hábito de entretenimiento diferente, "donde Internet está jugando un papel esencial, permitiendo - junto a la televisión - que el consumidor tenga una experiencia en el visionado de contenidos llegando a interactuar con ellos desde casa" (Ruano López, 2014, p. 280).

Los medios tradicionales, como la televisión, ya están ofreciendo contenidos multipantalla, y el espectador puede visionar contenidos audiovisuales digitales cómo, cuándo y donde quiera. Podemos ver de forma simultánea la emisión televisiva desde distintos dispositivos y por cualquier soporte: televisión, web, servicios de telefonía móvil, y gracias a las redes sociales, los usuarios pueden dejar sus comentarios y opiniones a través de la propia web, desde sus páginas de Facebook o sus cuentas de Twitter. Además, mediante las redes sociales, "los telespectadores están más informados de los contenidos exclusivos que pueden encontrar de sus emisiones favoritas y participar en concursos y juegos e incluso comentar la emisión de algunos programas en directo" (Ruano López, 2014, p. 281).

El grado de penetración de las redes sociales en los hábitos del consumidor las coloca en el centro de atención de gran parte de los procesos tecnológicos que sustentan a la denominada Sociedad de la Información. El modelo basado en la figura inmanente de emisor-mensaje-receptor parece sufrir una cierta mutación, o al menos establece las bases para el desarrollo de nuevos sistemas de interactividad (Sequera Díaz, 2013).

\section{La convivencia de la televisión tradicional con las nuevas pantallas}

¿Significa este panorama que la tradicional televisión de masas está en vías de desaparición? Missika (2006, p. 65) opina que "no parece que estemos en ese escenario". Todavía a la televisión convencional se la puede seguir considerando como el medio de comunicación hegemónico, ya que los datos de penetración siguen siendo espectaculares. Y no es un suceso aislado. En España, y según los datos del último 
Informe General de los Medios de febrero a noviembre de 2015, sitúa a la televisión en el primer lugar del ranking de penetración en la sociedad con un 88,3 por ciento, seguido de la publicidad exterior con un 69,3 por ciento $y$, en tercer lugar, encontramos a Internet, que le sigue muy de cerca con un 66,7 por ciento. Ya en cuarto lugar vemos a la radio con un 60,1 por ciento (AIMC, 2015b).

Tabla 1. Audiencia General de Medios España, febrero-noviembre 2015

\begin{tabular}{|c|c|}
\hline Medios & Penetración \% \\
\hline Televisión & 88,3 \\
\hline Publicidad Exterior & 69,3 \\
\hline Internet & 66,7 \\
\hline Radio & 60,1 \\
\hline
\end{tabular}

Fuente: elaboración propia sobre datos de AIMC (c) EGM

Este fenómeno es común a los principales países consumidores, con Estados Unidos a la cabeza, donde el consumo de televisión en los jóvenes adultos con edades comprendidas entre los 15 y 34 años supera las 3 horas diarias (Eurodata TV worldwide, 2015), aunque añadiendo un matiz importante: la mayor parte de ese tiempo de consumo, entre los más jóvenes, se produce utilizando segundas pantallas y visionando contenidos en diferido, aunque estos sean productos creados por $y$ para la industria televisiva. Esta realidad nos adentra en el hecho irrefutable de que, cada vez más, existe una migración de la "gran pantalla» hacia otros dispositivos, sobre todo entre los más jóvenes.

Pero ¿cómo es este solapamiento entre la televisión y el resto de pantallas?, ¿estamos ante la gran «revolución de las pantallas, soportes y dispositivos»? Lipovetsy y Serroy (2009) observaron estas transformaciones desde la perspectiva de las pantallas, que se han multiplicado a nuestro alrededor. Nunca tuvimos tantas: ordenador, teléfono móvil, tabletas, e-reader, televisión, set-top box. Puede ser que por esta realidad combinada, la última encuesta desarrollada por Digital TV Group Media Research (2014), entre más de 35.000 usuarios en el Reino Unido, ofrezca cifras como que el $43 \%$ de los usuarios de tabletas ve más televisión ahora que hace cinco años. No es de extrañar si tenemos en cuenta que el 65 por ciento de los españoles usamos cada una de nuestras pantallas en algún momento del día, y que el 35 por ciento llevamos a cabo un consumo de estas de forma simultánea (AdReaction-Milward Brown, 2014). 
La publicidad de las marcas en el escenario multipantalla

El sector de la comunicación corporativa y la publicidad se han aprovechado de todos estos elementos de cambio, afrontando un periodo de transformaciones necesarias, ya no solo por la utilización de la tecnología digital, sino que además han sabido adaptarse a nuevos lenguajes y a nuevas narrativas que, transfiriéndose al mercado digital de consumo, han abastecido a las técnicas de marketing revolucionando la forma en la que los contenidos y los mensajes comerciales consiguen integrarse. Costa-Sánchez (2014), pone de manifiesto que a este proceso se añaden elementos de agotamiento respecto de formatos publicitarios encumbrados en la época de la comunicación de masas como única correa de transmisión mediante la utilización del spot televisivo. La consecuencia de todo ello es la necesidad de comunicarse de otra forma. Y para dar respuesta a las transformaciones más urgentes de la función publicitaria, nace el branded content, un formato publicitario que más que persuadir pretende generar interés (Costa-Sánchez, 2014, pp. 84-86).

Tabla 2. Formatos publicitarios presentes.

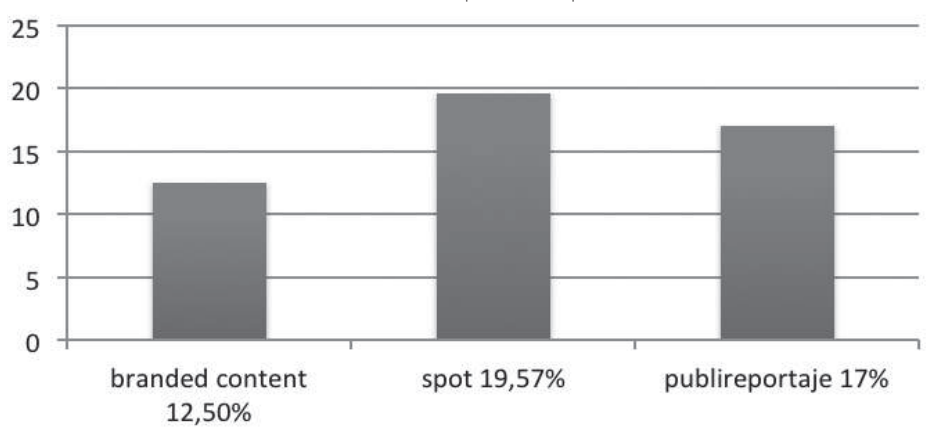

Fuente: elaboración propia sobre los datos del estudio «El cambio que viene. Audiovisual branded content». (C) Carmen Costa-Sánchez (2014) 
Al comienzo de esta década, Del Pino y Galán (2010), ya hablaban del triunfo de este formato como herramienta para la estrategia publicitaria. Más recientemente, La Ferle y Edwards (2006) y Tessitore y Geuens (2013), citados por Ortiz Sobrino y Montemayor Ruiz (2014), ponían de manifiesto, respectivamente, la eficacia de las marcas en televisión y la incidencia de la señalización en los emplazamientos publicitarios.

Dicen Segarra y Plaza (2012), que el brand placement y el product placement, como sistema de emplazamiento de marcas, son un instrumento de comunicación no circunscrito a los géneros televisivos, sino extrapolable a otros territorios, como el cinematográfico, el editorial, el musical, los vídeoclips o las webseries, entre otros.

Sin embargo, aunque para el emplazamiento de marcas publicitarias se han utilizado diferentes soportes desde hace años, es en los contenidos audiovisuales y en los formatos digitales multimedia donde las marcas, gracias al soporte en vídeo, han encontrado innovadoras formas de transmitir sus mensajes, consiguiendo, de esta manera, gran visibilidad a través de diferentes medios y plataformas. Por consiguiente, el contenido audiovisual sigue avanzando y siendo palanca de activación de diferentes estrategias. "El vídeo seguirá creciendo con múltiples fórmulas y formatos más allá del vídeo en players. El vídeo ya se ha convertido en una herramienta de comunicación y de notoriedad que facilita la construcción del branding" (IAB, 2015).

Dice Vaca Berdayes (2015), que el vídeo es el elemento esencial de esta nueva cultura digital, recalcando que este, sin duda, es la sangre del nuevo ecosistema audiovisual que hoy ofrece un mestizaje de medios y narrativas que hacen del mundo una aldea en permanente ebullición, donde el triunfo radica en la tecnología y, sobre todo, en los contenidos, que siguen siendo el magma de nuestro oficio. Ahora, y debido al avance de los medios digitales, tenemos la oportunidad de desarrollar contenidos con múltiples relatos, con historias paralelas interactivas y relacionadas entre sí, pero por encima de todo está el saber contar la historia. Y las historias son la mejor herramienta para conseguir captar a la audiencia, al usuario, "que es el verdadero motor de la industria audiovisual y la publicidad 
su principal nutriente" (Vaca Berdayes, 2015, p. 51).

\section{Una nueva forma de contar la publicidad}

Es evidente que el nuevo escenario multipantalla necesita una redefinición de las técnicas de narración audiovisual. Freitas y Castro (2010) y Anrubia (2002), coinciden en afirmar que lo que prima ahora es contar una historia. Una historia que surge de una narración, de un evento real o imaginario, oral o textual, que es actualizado por la mente del oyente o lector y traspuesto a un ambiente de representación. El secreto en cualquier forma de narración sigue siendo el mismo: tener una buena historia para contar y saber contarla. La narrativa digital es la base sobre la que se articulan los discursos en los medios, necesitando de una reflexión donde se introduzcan todos los parámetros que el uso de la tecnología está haciendo variar, tanto en el fondo como en la forma de construir y entender la realidad (García, 2015). Porque la necesidad de encontrar nuevas fórmulas de narrar a partir de la convergencia de los medios y la multiculturalidad, estructurando el relato en dos partes principales: el contexto general y los formatos y relatos (Guarinos Galán y Sedeño Valdellós, 2013), nos conduce a preguntarnos si existen unas narrativas analógicas y otras digitales. Como dice Gómez-Tarín (2013), son respuestas que están en el aire; incluso son preguntas sin respuesta, o bien la respuesta es demasiado evidente. En este contexto, Leslie Rule (2015), dice que "Digital Storytelling is the modern expression of the ancient art of storytelling".

Afirma Victorino Ramírez (2011), que se han realizado numerosas aproximaciones al concepto de "narrativa digital", componiendo un campo en construcción que ha evolucionado en relación con la evolución tecnológica. "Hoy, las tecnologías han introducido cambios en la manera como se crean, circulan y reciben los contenidos, además de influir en ideas que sustentan el modelo hegemónico de narración" (Victorino Ramírez, 2011, p. 11). Esta autora añade que la fuerza de la narrativa digital - en la actualidad- radica en la posibilidad de relatar de forma inmediata y en contacto permanente con el receptor. Esta formulación hipertextual abandona la autoridad narrativa de 
una única voz - que da solidez y coherencia al relato- para dar paso a una multitud de voces procedentes de los usuarios, "que se transforman en coautores de los contenidos y que encuentran en las diversas plataformas digitales una forma de expresión personalizada pero a la vez colectiva, recuperando, así, una memoria social" (Victorino Ramírez, 2011, p. 14).

Tubella, Tabernero y Dwyer (2008), afirman que la explosión tecnológica ha dado lugar a un conjunto de contenidos elaborados y distribuidos en torno a las TIC. Por su parte, Barbosa Filho y Castro (2008), dicen que en este desarrollo de las Tecnologías de Información y Comunicación, así como en la convergencia de medios y en la interactividad, se introduce un nuevo elemento en el proceso de comunicación, representado por el ámbito del retorno interactivo y la construcción del mensaje. Así, el proceso de la comunicación -entendido como la relación entre el emisor y el receptor para la transmisión de un mensaje- es modificado por el cambio de los medios de comunicación digitales, con la posibilidad para el receptor de producir y emitir sus propios contenidos audiovisuales. Según Castro (2008), la relación deja de ser unilateral para tornarse bidireccional y dialógica. Echegaray y Peñafiel (2011), comentan que la digitalización de los medios de comunicación ha generado cambios en la creación y difusión de los contenidos mediáticos y en el papel otorgado a las audiencias, añadiendo que "los entornos digitales utilizan el propio medio digital y su capacidad interactiva para saber qué expectativas tiene su audiencia en cuanto al producto en cuestión llegando a fomentar la participación de la audiencia en determinados procesos de creación del guión" (Echegaray y Peñafiel, 2011, p. 428).

Las comunicaciones digitalizadas han hecho converger en una misma matriz elementos sociales y tecnológicos que han dado lugar a un nuevo contexto mediático. Encontramos así nuevos soportes y plataformas de distribución de contenidos, nuevos intermediarios, nuevos agentes en la producción, nuevos hábitos de consumo y la necesidad de readaptación del sector industrial de productos audiovisuales así como estudiar el comportamiento de los ciudadanos ante las alternativas que se imponen frente a los medios tradicionales (Pérez 
Rufí y Gómez Pérez, 2013; Vaca Berdayes, 2015).

Bukbãrde, Čižmar, Skinča \& Stojilović (2014) sugieren que la narrativa oral ha desembocado en la narrativa digital, donde se han añadido nuevas herramientas multimedia que hacen que la narrativa digital se convierta en la matriz de la comunicación en esta era colonizada de mensajes instantáneos que son transmitidos de múltiples formas: blogs, lenguaje web, historias interactivas, hipertextos, videojuegos narrativos, podscats de audio y vídeo. Hoy, comunicar y expresar una idea de forma clara y efectiva requiere de habilidades prácticas, como usar las herramientas de forma correcta, así también como el lenguaje, y tenerlo en cuenta a la hora de aplicarlo al resto de aspectos para conseguir una comunicación efectiva. Pero aunque las historias digitales pueden, tan solo, incluir algunos elementos, como texto, imágenes y material de sonido, el verdadero poder de penetración e impacto de los mensajes se consigue cuando son utilizadas todas las herramientas que permiten difundir imágenes en movimiento, independientemente de la plataforma de distribución.
La televisión lineal y el fenómeno Internet, con YouTube a la cabeza, ofrecen la posibilidad de visibilidad e integración de las marcas en el contenido narrativo. Por consiguiente, el formato vídeo ha alcanzado un nivel de estandarización muy grande en el que se depositan las estrategias de venta y marketing visual digital. Según explican García et al. (2013), el nacimiento y éxito de YouTube se enmarca en el cruce de tres revoluciones: la de producción de vídeo, la de la Web 2.0 y la revolución cultural o de hábitos de consumo audiovisual. YouTube, por tanto, se ha convertido en el social media audiovisual por excelencia (CostaSánchez, 2014), y algunos de los motivos que conducen a las empresas a poner en marcha un canal en YouTube son la gratuidad, la enorme capacidad de almacenamiento y la alta popularidad del site, lo que favorece un feedback constante (Viana, 2009).

\section{Los nuevos canales de distribución como soporte para las marcas publicitarias}

Si YouTube se ha convertido en un canal para congregar a todos los actores - medios, cadenas de televisión, marcas, etc. - ¿Qué tipología 
de contenidos audiovisuales y formatos de vídeo se están utilizando para construir transmedia storytelling y/o branded content audiovisual en YouTube?

La respuesta la hallamos en un trabajo de investigación elaborado por Carmen Costa-Sánchez y publicado por la Revista Telos (no 99 ) de octubre de 2014 a enero 2015 bajo el título «El cambio que viene. Audiovisual branded content». La muestra estuvo conformada por las veinte primeras empresas del ranking 2013 en España, entre ellas, Mercadona, Inditex, Repsol, Iberdrola, Telefónica, BBVA, Ikea, Apple y Microsoft. El periodo de estudio abarcó del 2 de febrero al 6 de junio de 2014, tomándose una muestra de los 30 vídeos más recientes de cada canal. Los resultados de este trabajo fueron muy concluyentes, ya que se basaron en un amplio universo de estudio. Sus principales conclusiones indican que el nuevo formato de branded content está comenzando a introducirse en las estrategias audiovisuales de las marcas, pero por el momento su protagonismo es inferior al de las fórmulas clásicas tradicionalmente aplicadas a nivel publicitario. No obstante, un $49 \%$ de los vídeos analizados se integran en la vertiente publicitaria, lo que avala el empleo de YouTube como nuevo canal de comunicación con finalidad publicitaria. Dice Costa-Sánchez que YouTube se ha convertido en el social media audiovisual por excelencia. Permite subir a la Red vídeos de forma gratuita y generar conversaciones entre los usuarios mediante comentarios. En relación al branded content, su trabajo revisa otros anteriores, como el de Pérez Rufí y Gómez Pérez (2013), sobre las tendencias en géneros y formatos audiovisuales en el portal de referencia en vídeo online, YouTube, llegando a la conclusión de la importancia del vídeo online en las estrategias de las marcas. No en vano, España es el segundo país europeo en consumo de vídeo online, por detrás de Francia y por delante de Reino Unido o Alemania. Los datos del último informe de audiencia en Internet ofrecido por AIMC (2015a) sitúa a YouTube como el site más visitado durante el mes de mayo de 2015 con 22,5 millones de visitas, muy por delante de otras plataformas que ofrecen contenidos audiovisuales, como Antena3.com (2,6 millones) o RTVE.es (2,1 millones) (Costa Sánchez, 2014). 


\section{Material y método}

El objeto de este trabajo ha sido el vídeo como soporte de contenidos de branded content distribuidos a través de YouTube, Vimeo o mediante los smartphones y otros dispositivos utilizados como herramientas de descarga de contenidos. El objetivo del estudio que ahora se presenta se ha centrado en analizar la presencia del formato videográfico como contenedor de los relatos construidos mediante el branded content en esos dos canales de distribución de contenidos -You Tube y Vimeo- asociados a la convergencia mediática e Internet en tres campañas de éxito de las marcas Red Bull, Estrella Damm y Coca Cola. Las tres campañas han sido localizadas en Internet en un periodo de estudio comprendido entre octubre de 2012 y octubre de 2015.

La selección de las plataformas de distribución de vídeo online se ha realizado con base en diversos factores: relevancia, notoriedad y penetración en el mercado. También se ha tenido en cuenta en la selección de las plataformas el gran número de impactos obtenidos por estas firmas comerciales a través de YouTube y Vimeo fundamentalmente.

La elección de las campañas se ha determinado eligiendo tres bebidas, uno de los sectores de consumo más popular en España. Concretamente, Coca Cola, Red Bull y cerveza Estrella Damm. Estas marcas diseñan producciones audiovisuales mediante piezas de vídeo de gran calidad y en alta definición como elemento diferenciador en sus planes de comunicación, y tienen como denominador común la utilización del formato branded content como fórmula para la construcción narratológica de sus contenidos audiovisuales.

En este trabajo se ha utilizado un método basado en técnicas de observación y estudio de contenidos branded content en las plataformas online seleccionadas para contextualizar, después, los resultados con los principales datos relativos al consumo publicitario online aportados por otras investigaciones realizadas desde el ámbito profesional, que han permitido llegar a encontrar unos resultados que responden al objetivo planteado. La combinación de datos contribuye y aporta una mayor información a los resultados, como ya se ha recogido en la literatura científica (Wimmer y Dominick, 1996).

La metodología empleada se ha basado en los análisis de las tres compañas de branded content de 
las marcas publicitarias antes mencionadas y en la observación de los dos canales de distribución de contenidos en vídeo seleccionados: YouTube y Vimeo. Previamente, se ha realizado una consulta de fuentes documentales que ha permitido una contextualización del escenario de las plataformas online YouTube y Vimeo como soportes de distribución de contenidos en formato branded content. Después, se ha analizado la capacidad expresiva de estos relatos en formato videográfico que circulan a través de los diferentes soportes (plataformas) online de distribución propiciados por la convergencia digital que, hoy, son herramientas habituales en las estrategias de la narración digital para la optimización de las campañas de marketing transmedia o de publicidad de marcas.

Para contextualizar mejor el trabajo de campo y los resultados, este análisis se ha completado con los datos de los últimos informes y estudios realizados por prestigiosas empresas en medición, análisis y consultoría de medios, marketing y publicidad online digital, como Thinkwith Google e IpsosMediaCT (2015); AIMC Internet (2015); AIMC Estudio General de Medios (2015); Eurodata TV worldwide (2015). Digital TV Group Media Research (2014); (AdReaction-Milward Brown, 2014); ADman Media, IAB Spain y TNS (2014), que aportan sus resultados cuantitativos y cualitativos sobre la presencia y penetración en el mercado del vídeo digital online en España y otros países de referencia, como Estados Unidos.

El cruce de datos obtenido del análisis de las tres campañas con los datos de audiometría de las empresas Thinkwith Google e IpsosMediaCT (2015) y ADman Media (empresa líder en distribución de vídeo online), IAB Spain y la consultora TNS, a finales de 2014, ha permitido extraer conclusiones y resultados sobre la publicidad de marca y su consumo a través de YouTube y los smartphones como plataforma de distribución de contenidos publicitarios

\section{Resultados}

Los resultados recogen los principales hallazgos del análisis de las tres campañas de branded content estudiadas. Su gran repercusión entre los usuarios de las plataformas YouTube y Vimeo justifican la elección de estos tres casos de análisis (Tabla 3). 
Tabla 3. Datos análisis campañas Branded Content de vídeo online:

Red Bull, Coca Cola y Cerveza Estrella Damm 201 2-20 15

\begin{tabular}{|c|c|c|c|}
\hline CAMPAÑA BRANDED CONTENT & PLATAFORMAONLNE & LanZAMIENTO/CREALIÓN CANAL & REPRODUCCIONES/SUSCRIPTORES/AUDIENCIA \\
\hline RED BULL STRATOS & YOUTUBE & $\begin{array}{l}\text { octuBRe } 2012 \\
\text { * CREACIÓN CANAL } 2006\end{array}$ & $\begin{array}{l}\text { - } 8 \text { millones en live-streaming } \\
\text { - } 5 \text { millones de usuarios únicos } \\
\text { - } \quad \text { total reproducciones y descargas desde } 2006 \text { : } \\
1.400 \text { millones }\end{array}$ \\
\hline $\begin{array}{l}\text { ESTRELLA DAMM CORTOMETRAJE } \\
\text { "VALE" }\end{array}$ & $\begin{array}{l}\text { YOUTUBE } \\
\text { VIMEO }\end{array}$ & $\begin{array}{l}\text { ABRLL } 2015 \\
\text { * COMIENZO CAMPAÑAS BRANDED } \\
\text { CONTENT } 2012\end{array}$ & $\begin{array}{l}\text { - 6,1 millones de reproducciones hasta octubre } \\
\text { de } 2015 \text { en youtube } \\
\text { - }+2 \text { millones de reproducciones hasta octubre de } \\
2015 \text { en vimeo }\end{array}$ \\
\hline COCA COLA JOURNEY-FAMILAS-ESPAÑA & $\begin{array}{l}\text { YOUTUBE } \\
\text { VIMEO }\end{array}$ & ABRIL 2015 & $\begin{array}{l}\text { - }+2,2 \text { millones de reproducciones hasta } \\
\text { noviembre de } 2015\end{array}$ \\
\hline
\end{tabular}

Fuente: elaboración propia según datos de @YouTube / ( Vimeo

La innovación y la generación de emociones es un valor añadido en cualquier formato de Branded Content: el caso Red Bull Stratos

En el caso de la campaña Red Bull Stratos en 2012, basada en el salto estratosférico de Félix Baumgartner, una de las operaciones de branded content más relevantes de los últimos años, se pone de manifiesto que hay una relación directa entre la notoriedad mediática y la forma de construir contenidos audiovisuales basados en la innovación, la creat ividad y la generación de sensaciones y emociones. La calidad de la producción ${ }^{1}$ y el diseño del proyecto contribuyeron a su difusión consiguiendo récord de audiencia a través de Internet. Según los datos

1 https://vimeo.com/48082757 ofrecidos por la compañía, la campaña tuvo ocho millones de usuarios únicos en vídeo live-streaming a través de YouTube el día final de la operación Red Bull Stratos. La emisión en directo del salto estratosférico de Félix Baumgartner no solo rompió la barrera del sonido con un salto en caída libre desde un globo que él mismo tripulaba y que llegó a rebasar los 39.045 metros de altura; también consiguió una enorme notoriedad en todos los medios. Dice Sturner (2012), citado por Montemayor Ruiz (2013), que el "valor para Red Bull de este evento es de decenas de miles de dólares dada su exposición global" (Montemayor Ruiz, 2013, p. 25). Pero eso no es todo, la consolidación de las estrategias digitales utilizadas en este acontecimiento ayudaron sobremanera a que el canal de la marca 
de bebidas energética más consumida en el mundo se consolidara. Desde 2006 se han suscrito al canal más de cinco millones de usuarios únicos y las estadísticas del canal señalan que el número de reproducciones ha alcanzado, a finales de 2015, la cifra de mil cuatrocientos millones de descargas a través del canal Red Bull en YouTube ${ }^{2}$.

\section{La historia videográfica narrada y el escenario son ya un formato de éxito para el Branded Content: el caso de Estrella Damm}

La firma catalana Cerveza Estrella Damm apuesta por el formato branded content. La campaña iniciada por esta marca en abril de 2015 , centrada en un producto audiovisual producido con una gran calidad técnica y artística - el cortometraje titulado "Vale" ${ }^{3}$, dirigido por Alejandro Amenábar y protagonizado por Dakota Jhonson y Quim Gutiérrez-, nos cuenta, en clave cinematográfica y videográfica, una historia que se relaciona directamente con la marca. En ella, más que en emplazar el producto, se crea un ambiente en el que la marca se respira, ya que los protagonistas forman parte del target objetivo de la campaña. Las referencias musicales en el vídeo, que se identifican con el público habitual de la marca, sirven de pretexto para que los protagonistas terminen bebiendo una Estrella Damm. En octubre de 2015, el vídeo de la campaña había alcanzado la cifra de 6,1 millones de reproducciones en YouTube y más de 2 millones en Vimeo. Su formato videográfico y duración (12 minutos, o lo que es lo mismo: la duración idónea para un long format en Internet), contribuyeron a su notoriedad en estas plataforma digitales. Con esta estrategia de branded content, la marca de cerveza continúa con la línea de marketing de contenido emprendida con la campaña Estrella Damm "mediaterráneamente" en 2012, con más de 3,5 millones de reproducciones hasta finales de 2015 y con la creación de su propio canal en YouTube ${ }^{4}$.

2 https://www.youtube.com/user/redbull/ videos? flow $=$ grid\&sort=p\&view $=0$

3 https: / / www.youtube.com / watch? $v=6$ j|QiwcsV9Q https: //vimeo. $\mathrm{com} / 130973628$

4 https://www.youtube.com/user/TheEstrellaDamm/videos https://vimeo. $\mathrm{com} / 44248155$ 
Las sensaciones y los sentimientos como contendedores del Branded Content en soporte videográfico distribuido a través de YouTube: el caso de Coca Cola

La marca Coca Cola sigue enfocando su estrategia publicitaria en la felicidad y no en el propio producto, aunque este aparece en situaciones cotidianas en las que se puede considerar normal consumir un refresco. El vídeo analizado para este estudio, "Coca Cola Journey España-familias" ${ }^{5}$, muestra a una serie de niños que plantean cuestiones que han oído en el colegio, por parte de sus compañeros, relacionadas con su familia o con sus progenitores. El núcleo narrativo se centra en las preguntas que los niños se hacen: ¿por qué tienen dos papás?, ¿por qué su mamá es mayor que las otras mamás?, ¿ por qué sus padres no son sus padres biológicos? Todas estas situaciones finalizan con la pregunta de si seguirían eligiendo a sus padres tal y como son, a lo que ellos responden con un sí. Con más de 2,2 millones de reproducciones desde abril de 2015 -datos ofrecidos en el portal YouTube-, esta campaña de Coca

5 https: / / www.youtube.com / watch? $\mathrm{v}=\mathrm{DO}$ ctwr $5 \mathrm{McJc}$
Cola presenta los diversos tipos de familia que se pueden dar en la actualidad, y nos muestra, mediante una secuencia de diálogos muy entrañables entre padres e hijos, que no existe una fórmula única para conseguir la felicidad. Branded Content en estado puro.

La firma de refrescos Coca Cola lleva muchos años construyendo campañas en las que se relaciona la felicidad con el consumo de su producto. No obstante, a esa relación de spots y anuncios en los que se hace mención al producto de forma discreta, pero que relatan experiencias diarias, la compañía, desde 2013, ha dado un paso más allá, convirtiendo su página web en una revista de tendencias, Journey, toda una declaración de principios que supone uno de los mejores ejemplos de branded content.

\section{Los smartphones son} protagonistas y herramientas esenciales para la distribución y captación de los contenidos de Branded Content

Este alto consumo de contenidos audiovisuales se realiza, en gran medida, utilizando los dispositivos móviles de la llamada "cuarta pantalla", 
los smartphones, que se han convertido en la herramienta preferida para el visionado de vídeos a través de distintas plataformas, entre otros motivos, por la proliferación en el mercado de terminales que disponen, cada vez más, de enormes posibilidades de inmersividad e interactividad gracias a las prestaciones que ofrecen; entre ellas, la capacidad de visionar vídeos en alta definición, en definición $2 \mathrm{k}$ y en ultra alta definición $4 \mathrm{~K}$. Este hecho redunda en la adaptación que la industria audiovisual está realizando a la hora de adecuar tecnología y narración ante este nuevo escenario de consumo, donde el branded content se sitúa como estrella protagonista emergente de un negocio que utiliza el soporte de vídeo como factor esencial para la construcción de las marcas. Este nuevo teatro de operaciones está siendo analizado por las más prestigiosas firmas en consultoría e investigación relacionadas con el marketing, el diseño de marca y el hábito de consumo en el mercado publicitario. En este trabajo, como ya se ha adelantado, se han examinado algunos de estos informes, que corresponden con las últimas publicaciones que han salido a la luz en los años 2014 y 2015.
Los usuarios de smartphones tienen un amplio consumo de contenidos de marcas integradas

Destacamos un reciente estudio de Thinkwith Google e IpsosMediaCT (2015) sobre construcción de marca en móviles en EE.UU. en el que se afirma que los usuarios de smartphones son más proclives a consumir y compartir anuncios y contenido de marcas, sugiriendo que las personas que experimentan el visionado de vídeos en sus terminales móviles poseen 1,4 veces más probabilidades de consumir anuncios que los que ven vídeos en sus ordenadores o televisores. Además, los usuarios de smartphones no solo son más propensos a observar contenidos publicitarios, sino también a compartirlos. Las personas que ven publicidad en forma de spots o contenido de marca integrada, en una oferta audiovisual concreta, tienen 1,8 veces más de probabilidades de compartir contenidos que los que ven esos contenidos en ordenadores (Ver Tabla 4). 
Tabla 4. Los espectadores de smartphones

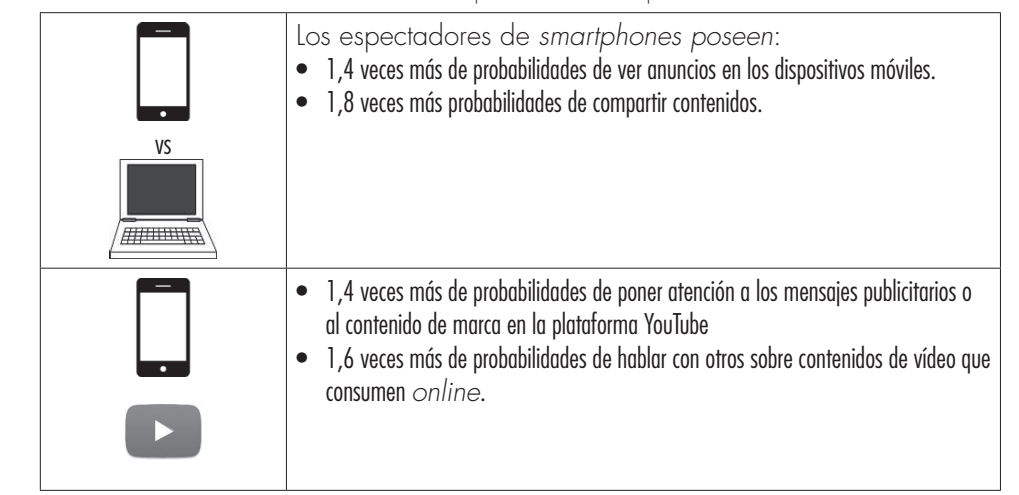

Fuente: elaboración propia sobre los datos Google/Ipsos (Brand Building on Mobile Survey [U.S.], febrero de 2015

Los espectadores de smartphones, que consumen vídeos online "tienen 1,6 veces más probabilidades que los telespectadores de hablar en persona con otros sobre el contenido de vídeo que están viendo" (Thinkwith Google e IpsosMediaCT, 2015). Además de ser probable que los espectadores de vídeo en smartphones vean y compartan mensajes publicitarios y contenido de marcas, tienen casi el doble de probabilidades que los telespectadores de sentirse conectados personalmente con las marcas que muestran anuncios o contenidos de vídeo en sus dispositivos y 1,3 veces más de probabilidades que los espectadores en ordenadores. Este hecho resulta intuitivo si se tiene en cuenta la naturaleza de la visualización de vídeos en un smartphone: es una experiencia más íntima y personal que verlos en un ordenador o por televisión. Parece natural que el vídeo para móviles sea el lugar en el que las marcas pueden crear conexiones personales (Thinkwith Google e IpsosMediaCT, 2015).

\section{Los subgéneros y los nuevos formatos para el Branded Content: un especial protagonismo de la información y el entretenimiento}

En relación a qué géneros se están desarrollando en YouTube, predomina el subgénero informativo, es decir, prácticas de branded content que pretenden aportar información interesante para el usuario (66\%), debido, en parte, porque se percibe a YouTube como un repositorio de vídeos más que un canal destinado a conversar y a desarrollar 
dinámicas interactivas. En segundo lugar se encuentran los formatos de entretenimiento (19\%), mientras que en el tercer lugar se detecta una finalidad educativa (15\%), tal y como se pone de manifiesto en la siguiente imagen (Figura1).

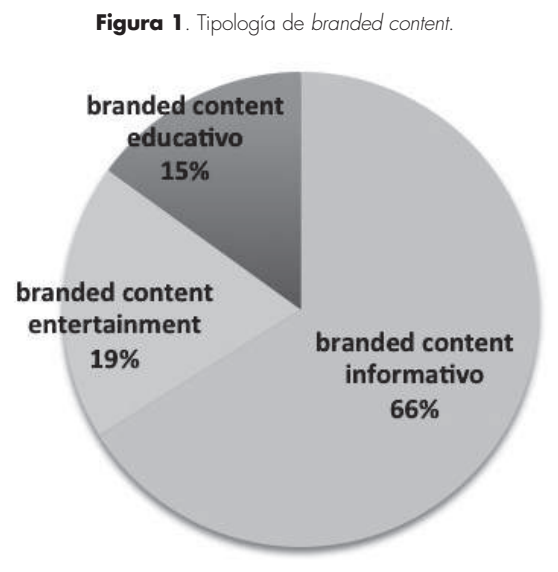

\footnotetext{
Fuente: elaboración propia sobre los datos del estudio «El cambio que viene. Audiovisual branded content». (C) Carmen Costa-Sánchez (2014)
}

Estos resultados contrastan con la oferta que YouTube ofrece a partir de las piezas producidas y divulgadas por los usuarios activos en el portal, a los que se denomina de forma genérica como youtubers. La primera diferencia con respecto a las industrias del audiovisual o el marketing digital de marca es que la génesis del producto vídeo procede de su creación específica para distribución online. Siguiendo las tipologías barajadas por Pérez Rufí y Gómez Pérez (2013), los nuevos formatos cuya autoría corresponde a estos youtubers, son los siguientes:

Remix. Adaptación o reelaboración del producto audiovisual producido por otros agentes dando lugar a un nuevo contenido.

Fandom. Describe todo lo que tiene que ver con la actividad creativa de los fans, entendido este como seguidor activo.

Lip-dub. Se trata de un vídeo musical en el que no es su intérprete, sino un grupo numeroso de personas el que participa, cantando (moviendo los labios), bailando y realizando diferentes acciones, de forma coreografiada y planificada, al ritmo de una canción concreta. Con una peculiaridad, utiliza el plano secuencia y la óptica gran angular como elementos de su discurso audiovisual.

Habilidades artísticas. Este tipo de vídeo recoge las óptimas cualidades de un usuario. Ejemplos: en la interpretación musical o cualquier otro tipo de habilidad extraordinaria que posee el usuario en algún tipo de manifestación artística concreta. 
El vídeo-blog testimonial. Adaptación directa del blog personal textual y del podcast sonoro a las posibilidades que permite el audiovisual para el usuario.

Webisodes. Piezas de ficción que se integran dentro de una serie con unidad narrativa y continuidad, creados de forma específica para ser distribuidos a través de Internet, ya sea en páginas web o en YouTube.

Sketches. Son piezas de humor (en formato ficción low cost), que muestran situaciones cómicas o absurdas por parte de los usuarios que interpretan personajes. Con una característica: no poseen continuidad en varias entregas o piezas.

Animaciones. Se trata de una técnica a través de la cual se puede hacer una narración perteneciente a alguno de los géneros anteriores, como el sketch, el remix, el webisode o el fandom.

El caso español: el $80 \%$ de los encuestados manifiestan ser usuarios del vídeo marketing online

Los datos han sido extraídos del primer estudio sobre el uso del vídeo en la publicidad online y el marketing digital en España, basado en una encuesta realizada a directivos de las más importantes empresas. La encuesta ha sido realizada conjuntamente por ADman Media (empresa líder en distribución de vídeo online), IAB Spain y la consultora TNS a finales de 2014 (ADman Media, IAB y TNS, 2014).

Los datos ofrecidos en este estudio en relación a las tendencias generales del «online vídeo marketing» en España muestran que 8 de cada 10 encuestados ha utilizado el vídeo como herramienta de marketing durante 2013; 9 de cada 10 profesionales afirma que el vídeo online tiene impacto positivo en su empresa, que el aumento en el presupuesto invertido en vídeo online durante 2014 ha sido de un $38 \%$ y que el branded content es el formato de vídeo online más utilizado en 2013 y 2014.Durante 2013 la tipología más utilizada ha sido la del vídeo de contenido o branded content $(77,4 \%)$, seguido por el publicitario short format $(52,4 \%)$ y el vídeo long format (23,8\%).

Entre sus principales conclusiones, el estudio señala las siguientes:

a) la construcción de marca es el principal objetivo a la hora de integrar el vídeo en las estrategias de marketing. 
b) los portales de vídeo como YouTube son la opción favorita de 8 de cada 10 encuestados.

c) seis de cada diez entrevistados tienen previsto incluir el vídeo en sus acciones de publicidad online durante 2014-2015.

d) el vídeo online se posiciona como el formato más efectivo para conseguir engagement.

e) ocho de cada 10 profesionales están al día de las últimas noticias de vídeo marketing.

f) la viralización se considera la principal ventaja del uso del vídeo online.

Estos datos de índole cuantitativa sustentan la tesis de la enorme proliferación del vídeo online en las estrategias de marketing de marcas, sobre todo, a la hora de enfocar el formato branded content como el más efectivo a la hora de cumplir con los objetivos de penetración en el mercado.

\section{Conclusiones}

El contenido audiovisual cobra, sin duda, un papel protagonista en Internet, y la publicidad está obligada, por tanto, a adaptarse a esta realidad tanto en producción como en tecnología y modelos de comercialización. El vídeo online, verdaderamente, se conforma como el nuevo negocio digital. En este contexto, Internet ha tenido tal auge en las últimas décadas que ha pasado de ser un simple medio de comunicación a una oportunidad de negocio que está marcando a toda una generación, donde la creación de contenidos audiovisuales, que pueden ser compartidos mediante diferentes plataformas, como YouTube o Vimeo, ha ayudado a progresar a la industria publicitaria en consonancia con el crecimiento de la denominada "Generación Milennial", aquella que está integrada por los jóvenes de entre 20 y 35 años de edad, quienes se caracterizan por poseer enorme habilidad en el manejo de múltiples plataformas tecnológicas al mismo tiempo que manifiestan un empuje innovador constante.

Hoy, los usuarios de Internet son consumidores de vídeo online, sobre todo de productos de ocio y entretenimiento. Las marcas se han percatado de este hecho y han comenzado a trabajar los contenidos con gran carga creativa, consiguiendo construir, mediante el formato de branded content, una comunidad de fieles seguidores de la marca, 
alcanzando impactos allí donde antes simplemente cosechaban espectadores. Estos, ahora, interactúan y contribuyen a viralizar los mensajes. ¿Quién no ha compartido un vídeo o un enlace a un site como Vimeo o Youtube con un contenido determinado?

A tenor del presente estudio, el diagnóstico debe partir de un hecho constatado: el aumento en paralelo de la oferta y la demanda de vídeo. Uno de los motores de crecimiento del consumo de vídeo online es, sin lugar a dudas, la universalización del uso de las redes sociales, que favorece la difusión de este tipo de contenido. Este fenómeno tiene implicaciones que, para las marcas, van más allá del ámbito publicitario, afectando de forma directa a su estrategia de comunicación digital.

Por otra parte, al analizar las cifras del consumo de vídeo en Internet, es fácil percatarse de que la televisión, si la asimilamos a los contenidos audiovisuales, no solo no ha muerto, sino que podríamos decir que vive su mejor momento. A los buenos datos de consumo de TV convencional que registran los audímetros, habría que sumar el aumento imparable del consumo de vídeo a través de Internet de productos televisivos, que en el momento actual vuelve a ganar impulso gracias a los smartphones y tablets. Y todo ello gracias a la posibilidad de ver vídeos en streaming. Esta tecnología ha revolucionado el consumo de vídeo, ya que ha posibilitado la distribución de contenidos multimedia a través de la red, donde el usuario consume los productos audiovisuales al mismo tiempo que se realiza la descarga. Por consiguiente, se puede afirmar que el vídeo se está convirtiendo en la plataforma de comunicación con mayor proyección, y su uso se ha proliferado entre las empresas que desean diferenciarse de la competencia, obteniendo grandes beneficios; entre ellos, mejorar la imagen de marca entre los usuarios, tener mayor engagement, generar más tráfico en las website, dinamizar el contenido, aumentar la confianza y la credibilidad en los productos y fomentar la transparencia.

La relevancia de YouTube es notoria en relación a cualquier otra plataforma. Más de la mitad de los usuarios habituales de Internet declara ver vídeos a través de este canal diariamente, siendo YouTube el site más utilizado para visionado de contenidos audiovisuales. Este hecho irrefutable, avalado por los 
datos de penetración de esta plataforma, podría ser el argumento de peso esencial para dirigir las estrategias de vídeo marketing a YouTube, pero también la realidad nos sitúa en un escenario donde las marcas van a encontrar una alta densidad de competidores. La popularidad de YouTube contrasta, sin embargo, con la plataforma de vídeo para profesionales que permite publicar contenido sin intrusión publicitaria, Vimeo. Los contenidos de calidad son la esencia de esta plataforma, que premia una buena imagen, montaje y edición en comparación con YouTube. Con Vimeo, las marcas obtendrán una imagen de marca más sólida frente a sus seguidores, ya que estos pueden apreciar trabajos artísticos en full HD sin interrupciones y sin invasión de adblockers.

Por otro lado, cabe destacar que la gran mayoría de usuarios en España aboga por el modelo de gratuidad, basado en la publicidad, como forma de acceso a los contenidos. $\mathrm{Al}$ usuario no le gusta tener que ver anuncios a cambio de contenido, pero lo acepta, y de hecho, en muchas ocasiones, lo hace aun cuando podría evitarlo. Sin embargo, nuestra fidelidad ante algunas acciones de branded content y relatos transmedia, como en el caso Red Bull, supera con creces los posibles inconvenientes de un producto emplazado gracias a la estrategia desarrollada por la marca para integrar su imagen y sus mensajes perfectamente en los contenidos audiovisuales que produce, y cuya principal ventana es la plataforma YouTube.

\section{Referencias}

\begin{abstract}
ADMan Media, IAB Spain \& TNS (2014). Primer estudio sobre el uso del vídeo en la publicidad online en España, basado en una encuesta realizada a directivos de las más importantes empresas. Recuperado de https://www.admanmedia.com/static/docs/2014UsodelVideoenelMar ketingDigitalenEspana.pdf
\end{abstract}

AdReaction (2014). Marketing in a multiscreen world. Global Report. Recuperado de https://www.millwardbrown.com/adreaction/2014/ report/Millward-Brown_AdReaction-2014_Global.pdf
AIMC (2015a). Informe audiencia de Internet en el EGM. Abril-mayo 2015. [en línea] http://www.aimc.es/-Au- diencia-de-Internet-en-el-EGM- html Consultado 2 de Nov. 2015 
AIMC (2015b). Estudio General de Medios. Febrero a noviembre de 2015. Recuperado de http://www. aimc.es/-Datos-EGM-ResumenGeneral-.html

Anrubia, E. (2002). La estructura narrativa del ser humano I. Espéculo. Revista de Estudios Literarios. (21)

Barbosa Filho, A. y Castro, C. (2008). Comunicação digital - Educação, tecnologia e novos comportamentos. São Paulo: Paulinas.

Bukbãrde, S., Čižmar, Z., Skinča, A. \& Stojilović, I. (2014). Módulo 2. Narrativa digital. Curso de alfabetización multimedia. Recuperado de http://es.slideshare.net/Fundacionesplai/tma-avanzado-mdulo-narrativa-digitales-46931673

Bustamante, E. (2008). La televisión digital. En León, B. (Ed.): Transformar la realidad. Otra televisión es posible. Sevilla: Comunicación Social; 22-31.

Castro, C. (2008). Las Industrias de Contenidos en América Latina. Estudio realizado en el ámbito da Sociedade da Informação para la Comissión Económica para América Latina e Caribe (CEPAL)/ UNESCO/Chile. Recuperado de http://www.eclac.cl/ socinfo/noticias/ noticias/2/32222/

GdT_eLAC_meta_13.pdf

Costa-Sánchez, C. (2014). El cambio que viene. Audiovisual branded content. Telos (99), 84-93.

Costa-Sánchez, C. y Piñeiro Otero, T. (2012). Nuevas narrativas audiovisuales: multiplataforma, crossmedia y transmedia. El caso de Águila Roja (RTVE). Icono 14. Revista de Comunicación y Tecnologías Emergentes, 10(2), 102-125.

Del Pino, C. y Galán Fajardo, E. (2010). Internet y los nuevos consumidores: el nuevo modelo publicitario. Telos (82), 55-64.

Del Pino, C. y Olivares, F. (2006). Brand Placement: integración de marcas en la ficción audiovisual. Barcelona: Gedisa.

Díaz Arias, R. (2008). El vídeo en el ciberespacio: usos y lenguaje. Comunicar. Revista Científica de Educomunicación, 22(33), 63-71.

Digital TV Group Media Reasearch (2014). Assesing the impact of second screen. Recuperado de http://stakeholders.ofcom.org.uk/binaries/research/technology-research/2014/ Second_Screens_Final_report.pdf 
Echegaray, L. y Peñafiel, C. (2011), Convergencia y evolución en la creación de contenidos audiovisuales: un análisis sobre la percepción de la audiencia desde el punto de vista de los productores de contenidos. En I. Bort, S. García y M. Marín (Ed.) Nuevas tendencias e hibridaciones de los discursos audiovisuales en la cultura digital contemporánea, 427-439. Universidad Jaume I, Castellón: Ediciones de las Ciencias Sociales de Madrid. Recuperado de http://repositori.uji.es/xmlui/bitstream/handle/10234/31016/Echegaray_Penafiel_ActasIVCongreso. pdf?sequence $=1$

Eurodata TV worldwide (2015). Young Adults Report (Septembre 2014-Avril 2015). Les 15-34 ans: programmes phares, événemente et nouvelles practiques de visionage. Recuperado de http://www.mediametrie.fr/eurodatatv/communiques/young-adults-reportseptembre-2014-avril-2015.php?id=1345

Freitas, C. y Castro, C. (2010). Narrativas audiovisuales y tecnologías interactivas. Revista Estudios Culturales, (5), 19-42.

García, A. (2015). Los nuevos medios demandan nuevas narrativas.
Telos, Revista del Pensamiento sobre Comunicación, Tecnología y Sociedad, (100), 165-166.

García, A. et al. (2013). YouTube: la clave de los canales con mayor número de suscriptores en España. En J.P. Pérez Rufí (Coord.), Industrias audiovisuales: Producción y consumo en el siglo XXI, 6-28. Málaga: Universidad de Málaga.

Gómez-Tarín, F.J. (2015) Lo viejo y lo nuevo. Prólogo. En Guarinos Galán, V, y Sedeño Valdellós, A. M. (Coord.) Narrativas audiovisuales digitales. Convergencia de medios, multiculturalidad y transmedia. Recuperado de http://apolo.uji.es/fjgt/Prologo\%20Ana\%20Sedeno\%20B.pdf.

Guarinos Galán, V. y Sedeño Valdellós, A. M. (Coord.) (2013). Narrativas audiovisuales digitales. Convergencia de medios, multiculturalidad y transmedia. Madrid: La Fragua.

IAB Spain (2015). Top tendencias 2015. Informe anual IAB (Interactive Advertising Bureau) Recuperado de http://www.iabspain.net/wp-content/uploads/downloads/2015/01/ Top-Tendencias-20152.pdf

Irigaray, F. (2015). El periodista hoy debe pensar en múltiples pantallas, 
soportes y dispositivos. Recuperado de http://www.clasesdeperiodismo. com/2011/12/13/el-periodista-hoydebe-pensar-en-multiples-pantallas-soportes-y-dispositivos/ Consultado 30 Oct. 2015.

Jenkins, H. (2007) Nine Propositions Towards a Cultural Theory of YouTube. En Confessions of an Aca-Fan 28/5/2007. Recuperado de http://henryjenkins. org/2007/05/9_propositions_ towards_a_cultu.html

Lipovetsky, G. y Serroy, J. (2009). La pantalla global: cultura mediática y cine en la era hipermoderna. Barcelona: Anagrama.

Marta Lazo, C. y Ortiz Sobrino, M.A. (2013). Gestión de los fondos documentales en RNE. El profesional de la Información, 22, 5

Missika, J.L. (2006). La fin de la télévision. Paris: Seuil.

Montemayor Ruiz, F.J. (2013). Marketing experiencial en formato digital y en alta resolución: un nuevo paradigma en la retransmisión televisiva de los eventos. Vivat Academia. Revista de Comunicación (25), 17-35 DOI:http://dx.doi. org/10.15178/va.2013.125.17-35
Montemayor Ruiz, F.J. (2014). Postproducción digital e infografía virtual en la retransmisión televisiva de los eventos mediáticos. En Javier Sierra Sánchez y Francisco García García (Coord.), Tecnología y narrativa audiovisual, 51-73. Madrid: Editorial Fragua.

Montemayor Ruiz, F.J. (2015). La retransmisión televisiva de los eventos mediáticos en la era digital. Tesis doctoral, Facultad de Ciencias de la Información, Universidad Complutense de Madrid. Recuperado de http:// eprints.ucm.es/31374/1/T36257.pdf

Ortiz Sobrino, M.A. y Montemayor Ruiz, F.J. (2014). Publicidad dinámica y plataformas digitales. Brand placement en espacios públicos y transmisiones deportivas en televisión. Telos (99), 94-103

Pérez Rufí, J.P. y Gómez Pérez, F.J. (2013). Nuevos formatos audiovisuales en Internet: cuando el usuario es quien innova. En Isabel de Salas Nestares y Enric Mira Pastor (Coord.) Prospectivas y tendencias para la comunicación en el siglo XXI, 167-187. Madrid: Ediciones CEU.

Ràfols, R. (2011). Infografía audiovisual: de la imagen al espacio. 
Estudios sobre el mensaje Periodístico, 17(2), 569-579.

Ruano López, S. (2014). La televisión 3.0 y los nuevos formatos. En Javier Sierra Sánchez y Daniel Rodríguez Parente (Coord.) Contenidos digitales en la era de la sociedad conectada, 277-288. Madrid: Editorial Fragua.

Rule, L. (2015). Digital Storytelling Association. Recuperado de http:// electronicportfolios.com/digistory/

Segarra, J. y Plaza, A. (2012). Del product placement al brand placement en la ficción audiovisual: el caso de Puleva en El Internado. Comunicación: Revista Internacional de Comunicación Audiovisual, Publicidad y Estudios Culturales, (10), 1597-1609.

Sequera Díaz, R. (2013). Televisión y redes sociales: nuevo paradigma en la promoción de contenidos televisivos. Ámbitos. Revista Internacional de Comunicación (22).

Thinkwith Google e IpsosMediaCT (2015). Por qué el vídeo online es imprescindible en tu estrategia de marketing en móviles. Recuperado de https://www.thinkwithgoogle.com/intl/es-es/article/ por-que-el-video-online-es-imprescindible-en-tu-estrategia-de-marketing-en-moviles/

Tubella, I., Tabernero, C. y Dwyer, V. (2008). Internet y la televisión: La guerra de las pantallas. Barcelona: Ariel.

Vaca Berdayes, R. (2015). Televisión, pantallas y convergencia digital. Academia TV. Revista de la academia de las ciencias y las artes de la televisión. (137), 50-53.

Viana, J.A. (2009). YouTube como veículo de divulgação da comunicação corporativa. Centro Universitario de Brasilia. Recuperado de http://repositorio.uniceub.br/handle/123456789/2131

Victorino Ramírez, B.A. (2011). ¿Narrativa digital o digitalización de la narrativa? Tesis de Magíster. Facultad de Artes, Instituto de Estudios en Comunicación y Cultura, IECO. Universidad Nacional de Colombia. Recuperado de http:// www.bdigital.unal.edu.co/5218/

Wimmer, R.D. y Dominick, J.R. (1996). La investigación científica de los medios de comunicación: Una introducción a sus métodos. Barcelona: Bosch. 